\title{
The Yield Behavior of Leighton Buzzard Sand in a Hollow Cylinder Apparatus
}

\section{Pat Naughton}

Institute of Technology, Sligo, Ireland

email: naughton.patrick@itsligo.ie

\section{Brendan O'Kelly}

University of Dublin, Trinity College, Ireland

email: bokelly@tcd.ie

\section{Introduction}

The yield behavior of Leighton Buzzard sand was studied under generalized stress conditions using a hollow cylinder apparatus. Segments of yield surfaces were determined from identically prepared, hollow cylindrical test specimens of the sand.

The experimental yield data was compared with the theoretical values predicted by the Mohr-Coulomb, Matsuoka-Nakai and Lade yield criteria to establish whether these criteria are suitable for predicting the onset of yielding in sand under generalized stress conditions.

\section{Yield Criteria}

\section{Mohr-Coulomb}

$\frac{\sigma_{1}^{\prime}-\sigma_{3}^{\prime}}{\sigma_{1}^{\prime}+\sigma_{3}^{\prime}}=$ Constant

where $J_{1}, J_{2}$ and $J_{3}$ are the first, second and third effective stress invariants, respectively

\section{Leighton Buzzard Sand}

\begin{tabular}{|c|c|c|c|c|c|c|}
\hline Property & $\begin{array}{c}\text { Coefficient of } \\
\text { uniformity }\end{array}$ & $\begin{array}{c}\text { Coefficient } \\
\text { of curvature }\end{array}$ & $\begin{array}{c}\text { Mean } \\
\text { particle } \\
\text { diameter } \\
\mathrm{D}_{50}(\mathrm{~mm})\end{array}$ & $\begin{array}{c}\text { Specific } \\
\text { gravity }\end{array}$ & $\begin{array}{c}\text { Maximum } \\
\text { void ratio }\end{array}$ & $\begin{array}{c}\text { Minimum } \\
\text { void ratio }\end{array}$ \\
\hline Value & 1.32 & 0.96 & 0.52 & 2.64 & 0.77 & 0.50 \\
\hline
\end{tabular}

Stress and deformation in the hollow cylindrical test specimens

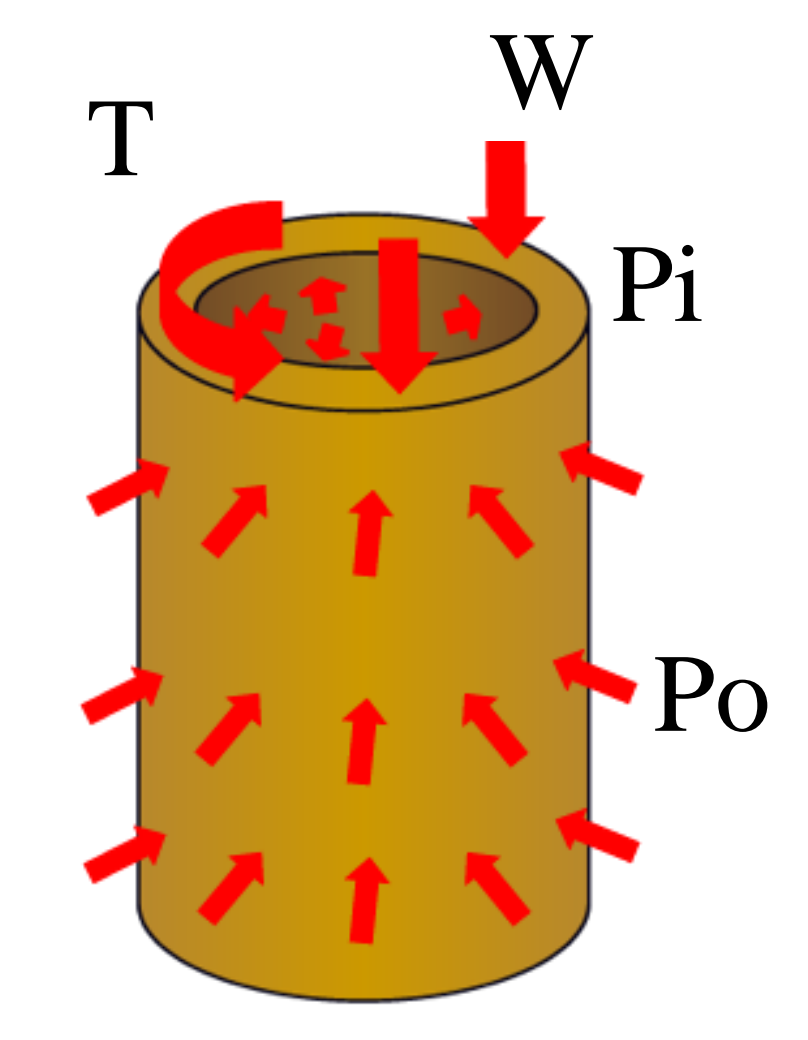

Applied tractions

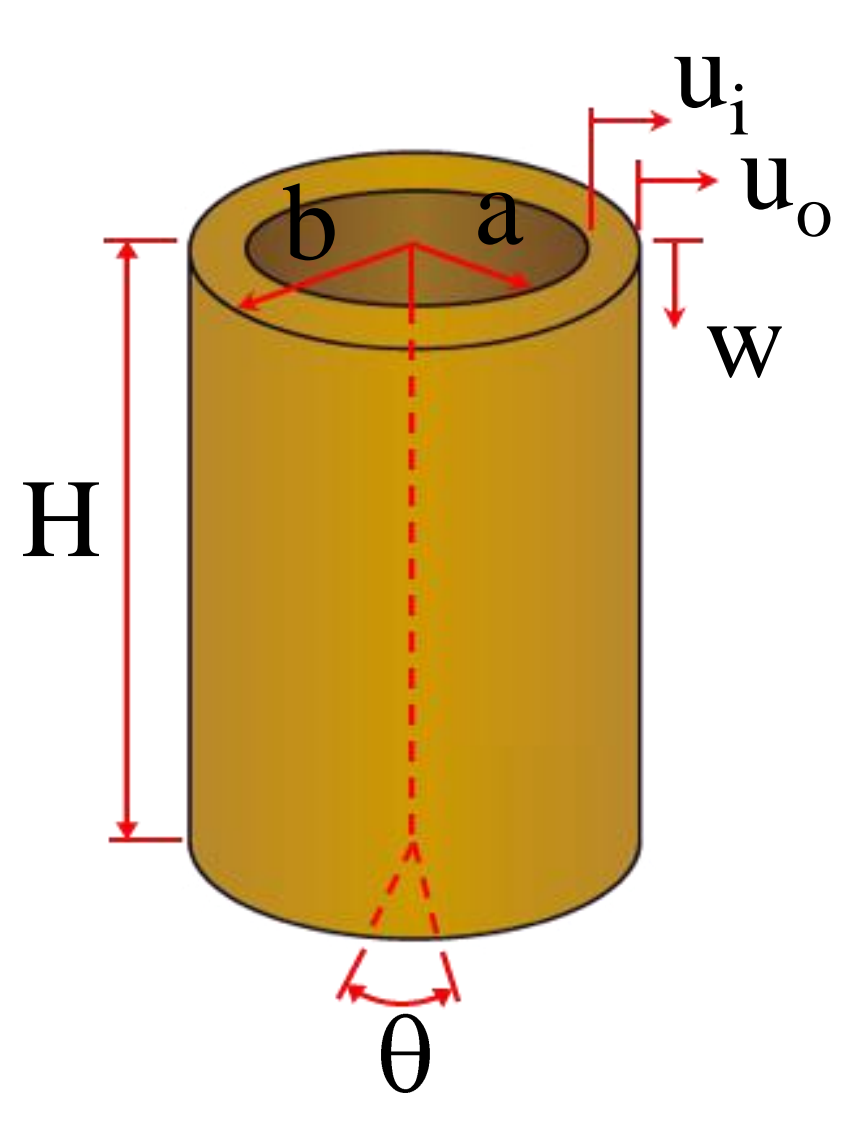

Specimen dimensions and deformations measured

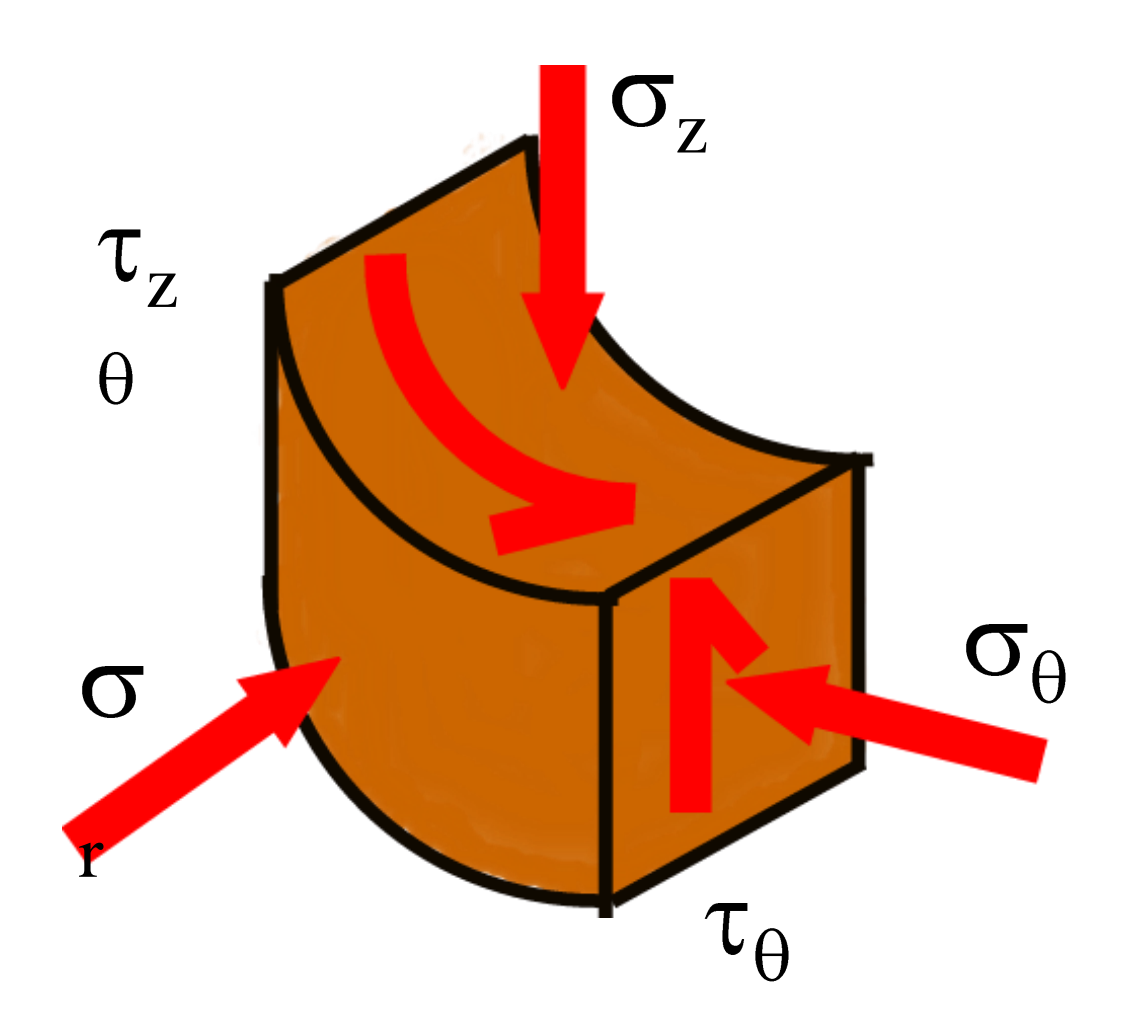

Sample normal stresses

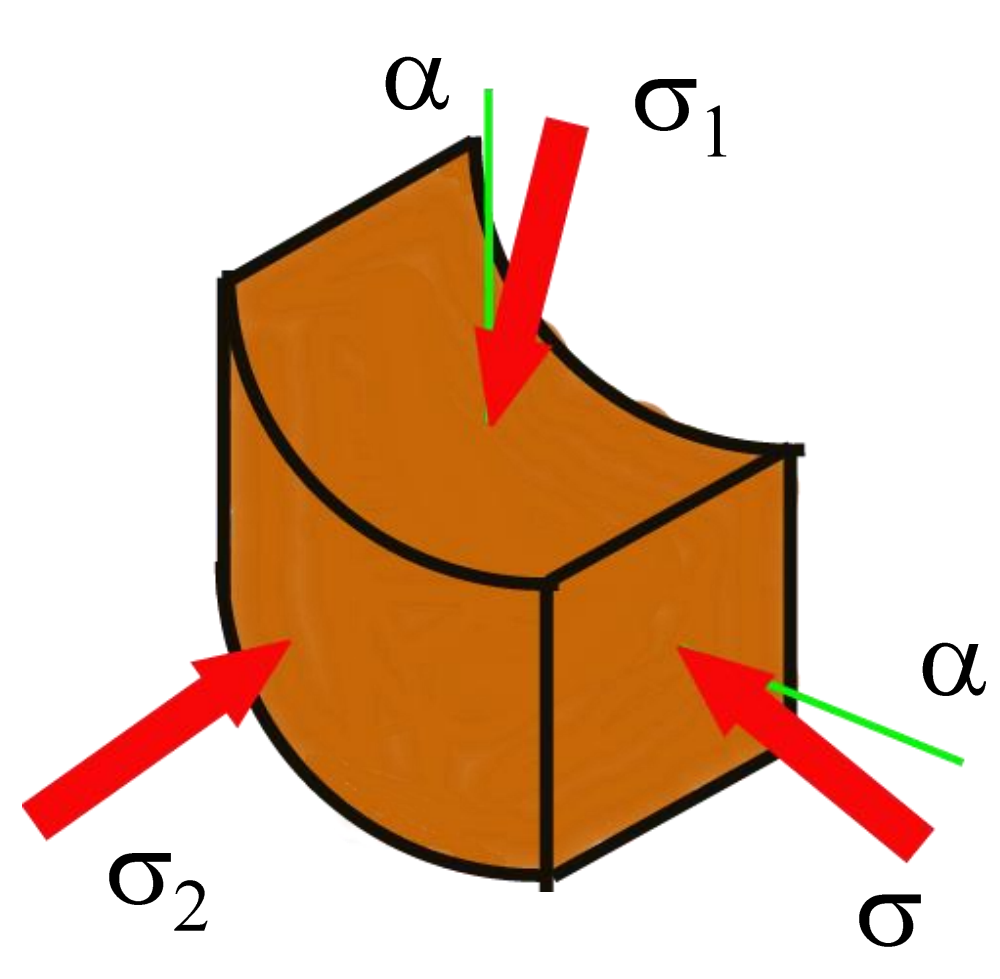

Principal stresses 


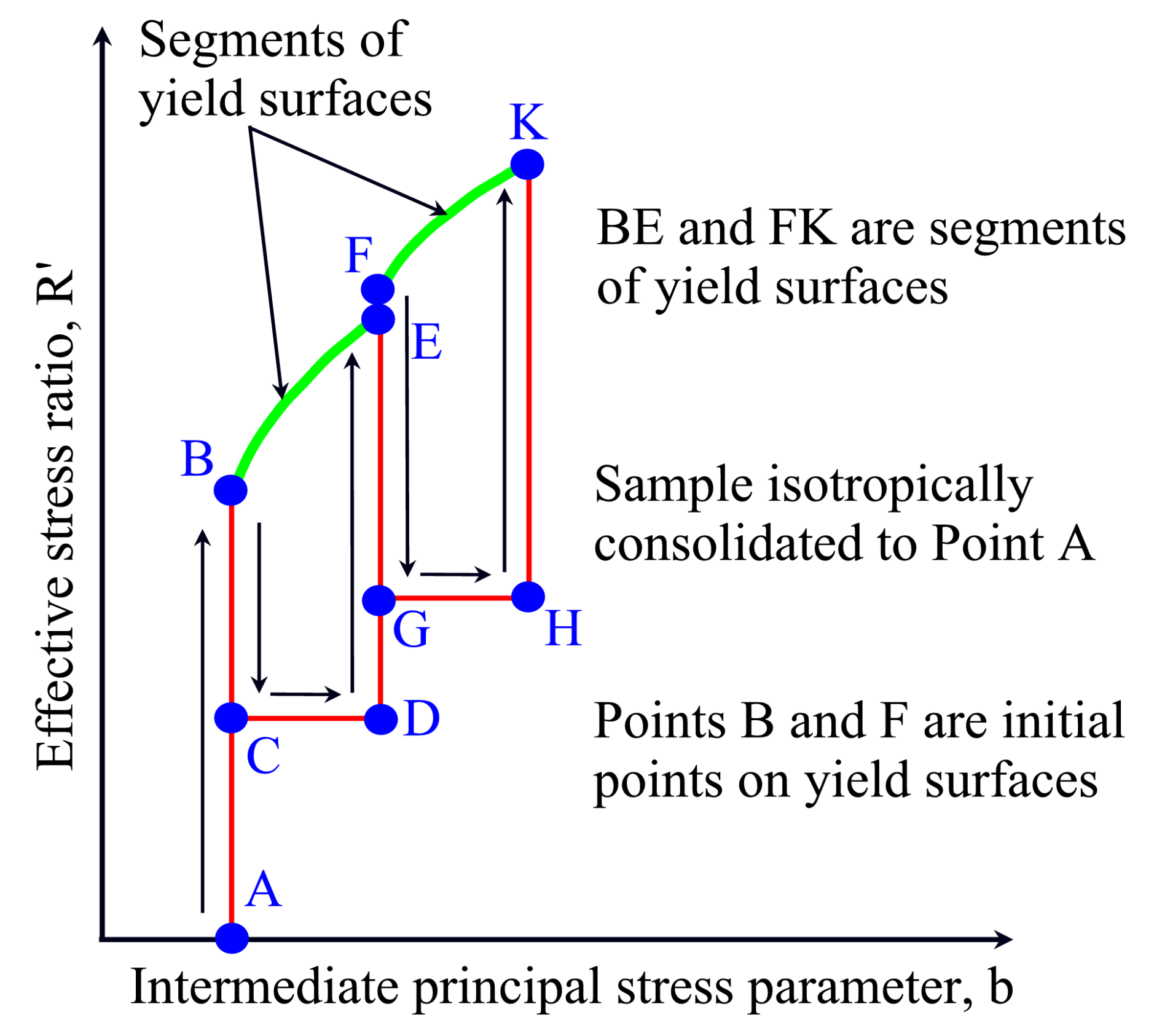

Typical stress path followed

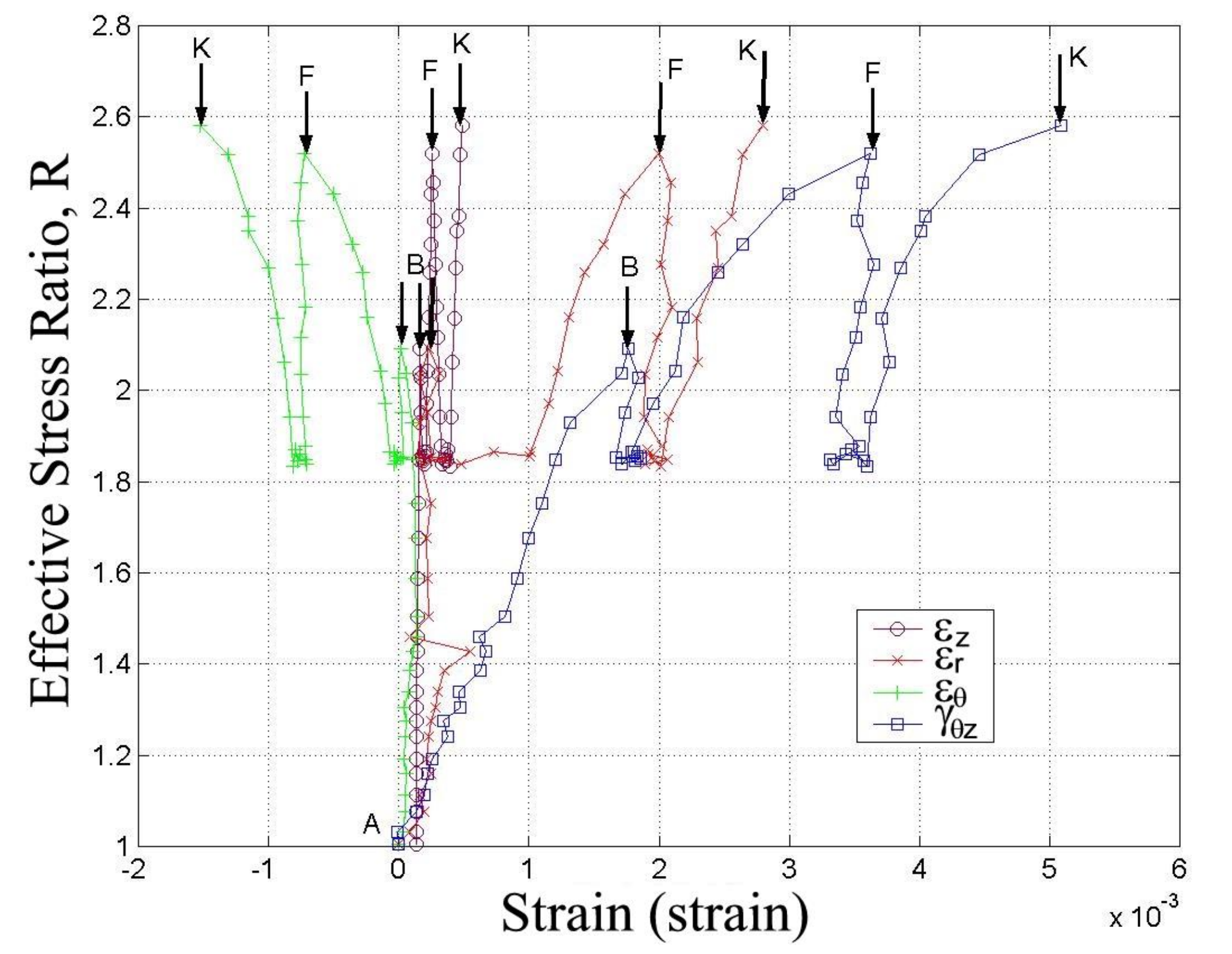

Stress-strain responses of test specimen Y0530
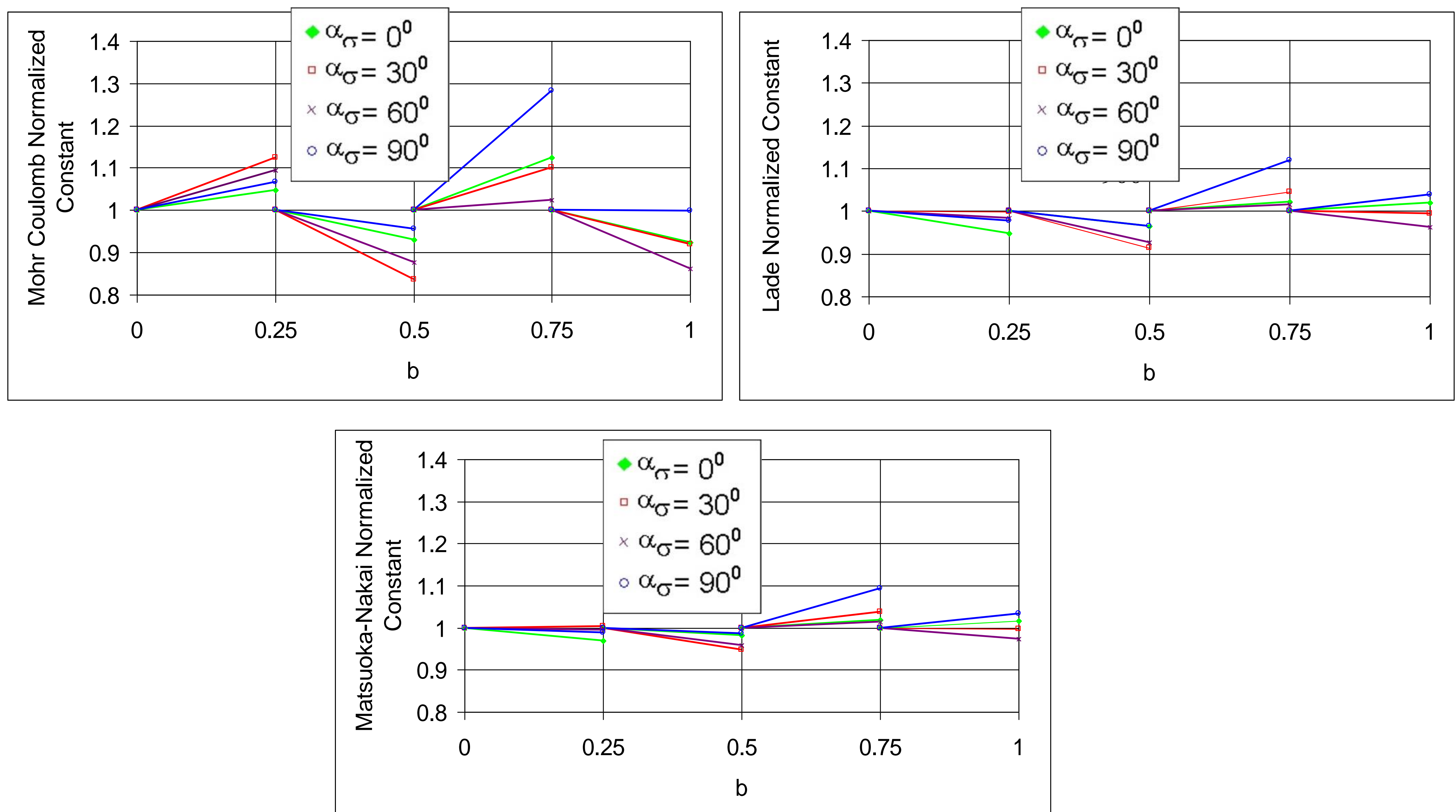

Experimental data expressed in terms of the Mohr-Coulomb, Lade and MatsuokaiNakai yield criteria

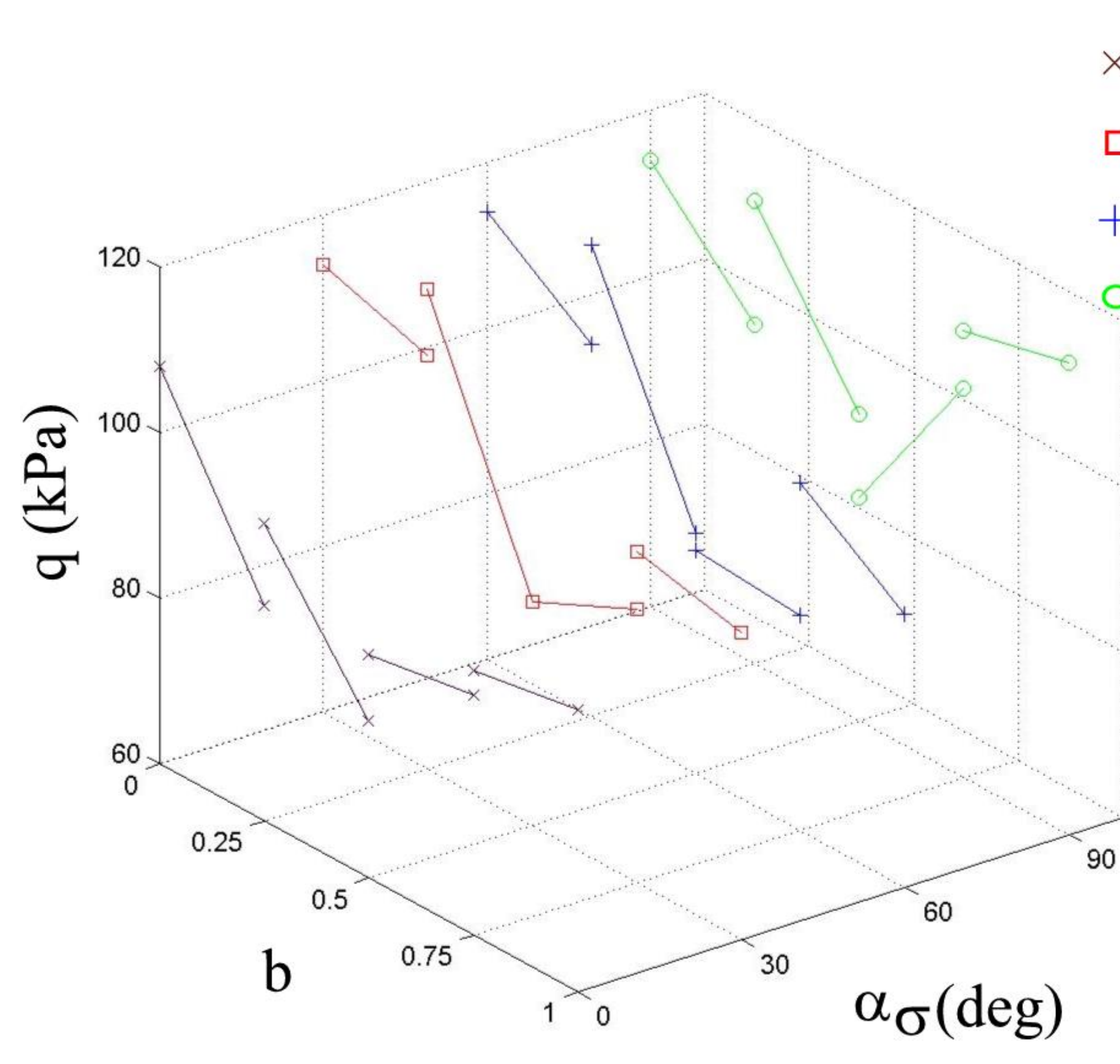

$\alpha_{\sigma}=0^{0}$

$\alpha_{\sigma}=30^{0}$

$\alpha_{\sigma}=60^{\circ}$

$\alpha_{\sigma}=90^{\circ}$
Variation of the deviator stress at yield in generalized stress space

\section{Conclusions}

The following points are concluded from this study of yielding in Leighton Buzzard sand:

1. The stress paths successfully identify segments of different yield surfaces in generalized stress space from identically prepared test specimens using a hollow cylinder apparatus.

2. The magnitude of the deviator stress at yield was dependent on the initial value of the $b$ parameter, but was largely independent of the magnitude of the rotation of the major principal stress.

3. The Matsuoka-Nakai and Lade yield criteria were both found to adequately predict the onset of yielding under generalized stress conditions.

4. The Mohr-Coulomb yield criteria generally deviated more from the theoretical values than the other two criteria examined and did not appear to follow a consistent pattern.

5. The experimental yield surfaces indicate that the prediction of yielding by all three criteria is predominately independent of the magnitude of the rotation of the major principal stress during the initial consolidation stage. 